\section{CLINICAL REPORT}

S.M. Lim

I.S. Choi

C.A. David

\title{
Spinal Arteriovenous Fistulas of the Filum Terminale
}

SUMmARY: The filum terminale is an anatomic structure at the end of the spinal cord. Only a few cases of AVFs of the filum terminale have been reported. These AVFs usually consist of a single communication between the anterior spinal artery and a single draining vein. We retrospectively analyzed the clinical and radiologic features and treatment of 4 patients with spinal AVFs of the filum terminale. Clinical manifestations and MR images are similar to those of spinal dural AVFs. All patients underwent surgical or endovascular treatment, resulting in complete occlusion. Clinical outcomes were good to excellent in all patients.

ABBREVIATIONS: $A S A=$ anterior spinal artery; $A V F=$ arteriovenous fistula; $A V M=$ arteriovenous malformation; $\mathrm{AVS}=$ arteriovenous shunt; Endovas = endovascular embolization; $n$-BCA = $n$-butyl cyanoacrylate; $\mathrm{SI}=$ signal intensity; $\mathrm{SV}=$ signal voids

$\mathbf{T}$ he filum terminale internum, commonly referred as the filum terminale, is a slender connective tissue filament, connecting the caudal apex of the conus medullaris at the L1-L2 level to the end of the dural tube at the second sacral level. It consists mostly of bundles of collagen fibers and some bundles of neurogenic tissue and is covered by the pia mater, extending from the conus throughout the intradural course. ${ }^{1-4}$ Vascular anatomy of the filum is unique. Its arterial supply is from 1 single longitudinal axis, which is the caudal extension of the radiculomedullary and anterior spinal arteries. It originates from the so-called vascular basket at the conus. Djindjian et $\mathrm{al}^{5}$ reported that the artery of the filum terminale is a ventral extension of the descending branch of the artery of Adamkiewicz. At the end of the conus medullaris, it may divide into 2 or 3 branches. One or 2 posterior branches are anastomotic channels with a pial network of the posterior spinal arteries. This longitudinal artery runs caudally and is located at the ventral surface of the filum because the anterior spinal artery runs in front of the spinal cord. Similarly, a single channel vein is also located on the ventral surface, but posterior to the arterial axis. ${ }^{6}$ Unlike its arterial counterpart, the vein of the filum terminale connects the extradural venous plexus in the sacrum to the ventral vein of the spinal cord. Venous flow can be either cephalad or caudad. ${ }^{5}$

Vascular malformations in the filum are rarer compared with the spinal cord or dural lesions, and only a few cases have been reported as a type of spinal AVM. AVFs of the filum terminale were initially described by Djindjian et al in $1977^{7}$ and were called "intradural extramedullary spinal AVFs." These were characterized by a direct AVS located on the ventral surface of the filum. ${ }^{8,9}$ Rodesch et al $^{10}$ found a 3.2\% prevalence of focal intradural terminal filum lesions (AVMs and AVFs) in their series of 155 patients with intradural AVSs. We

Received January 3, 2011; accepted after revision February 17

From the Department of Radiology (S.M.L.), Ewha Womans University Hospital, Seoul, Korea; and Departments of Radiology (I.S.C) and Neurosurgery (C.A.D), Lahey Clinic Medical Center, Burlington, Massachusetts.

Paper previously presented at: Annual Meeting of the World Federation of Interventional and Therapeutic Neuroradiology, June 29-July 3, 2009; Montreal, Ontario, Canada.

Please address correspondence to In Sup Choi, MD, Lahey Clinic Medical Center, 41 Mall Rd, Burlington, MA 01805; e-mail: In.sup.choi@lahey.org

http://dx.doi.org/10.3174/ajnr.A2612 have encountered 4 cases of AVF of the filum terminale with variable clinical symptoms. We report their clinical presentations, angioarchitecture, and treatment.

\section{Materials and Methods}

\section{Patients}

The cases were collected from the data base containing all the patients who had undergone angiography and/or endovascular treatment for spinal vascular diseases from January 1997 to September 2008. Four patients were diagnosed with arteriovenous shunts on the filum terminale. Two patients were men and 2 were women. The mean age of the patients was 56 years (ranging from 48 to 63 years). All patients had undergone MR imaging before referral to our service. Referral was based on clinical findings and MR imaging suggestive of a spinal AVM. All patients underwent selective spinal angiography. Medical records, spinal angiograms, and MR images were analyzed.

\section{Selective Angiography and Treatments}

Selective spinal digital subtraction angiography was performed via a femoral approach in a biplane neuroangiographic suite (Integris BN3000; Philips Medical Systems, Best, Netherlands). Standardized angiography included selective catheterization of all segmental arteries of the thoracic and lumbar levels and bilateral internal iliac arteries with the patient under general anesthesia. The cervical levels were excluded when a suspected vascular lesion was found. In 1 patient with thoracic venous congestion, complete spinal angiography was necessary with imaging of the cervical and upper thoracic spine via the bilateral vertebral, costocervical, and thyrocervical arteries. In segmental arteries, $4-6 \mathrm{~mL}$ of $240 \mathrm{mg} / \mathrm{mL}$ iodinated nonionic contrast material (iohexol, Omnipaque; GE Healthcare, Princeton, New Jersey) was injected, depending on the caliber of the individual artery, by a Medrad machine injector (Medrad, Indianola, Pennsylvania), and 13-14 $\mathrm{mL}$ was injected in the internal iliac artery. In case the median sacral artery was not visualized on iliac artery injection, the median sacral artery was catheterized selectively. Imaging was in the anteroposterior direction with 2 frames per second. Lateral views were added to elucidate the angioarchitecture of the fistula when a shunt was detected. We evaluated the origin of the radiculomedullary artery and the location of feeders and draining veins of AVSs. Following completion of mapping of an AVF, the decision as to surgery or endovascular treatment was made on the basis of the size of a feeding 


\begin{tabular}{|c|c|c|c|c|c|c|}
\hline \multicolumn{7}{|c|}{ Patient demographics, angiographic and MR imaging findings, and treatments of spinal AVFs on the filum terminale } \\
\hline No. & Age $(y r) / S e x$ & Feeder & Draining Vein & MR Imaging Findings & Fistula Site & Treatment \\
\hline 1 & 60/M & ASA from Lt L1 & Upward perimedullary & SV, high SI in conus & L3 & Surgery \\
\hline 2 & 48/M & ASA from Lt T10 & Upward perimedullary & SV, high SI in conus with swelling & L4-5 & Surgery \\
\hline 3 & $53 / \mathrm{F}$ & ASA from Rt L1 & Upward perimedullary & SV, high SI in T9 cord with swelling & $\lfloor 4-5$ & Endovas \\
\hline 4 & $63 / F$ & $\begin{array}{l}\text { ASA from Rt } L 4, \mathrm{Lt} \\
\text { lateral sacral artery }\end{array}$ & Upward perimedullary & SV & L3-4 & Endovas \\
\hline
\end{tabular}

pedicle and the distance from its origin from the segmental artery. The surgery was performed when the caliber of the anterior spinal artery was small and its course was tortuous. For embolization of the feeding pedicles, we used $n$-BCA and/or detachable coils.

\section{Results}

The patients and angiographic and MR imaging characteristics are presented in the Table. Clinical manifestations of the patients were sensory change in all patients, bladder/bowel dysfunction in 3 ( 1 patient with congenital spina bifida had a permanent ileal conduit), progressive motor weakness in 3 patients, and buttock pain in 2 patients. One patient (patient 4) had congenital spina bifida deformity at L4-5, causing serious weakness of the lower extremities and scoliosis. She had been able to ambulate with Canadian crutches until 18 years ago when she became wheelchair-bound. She was married and had 3 children by normal delivery. Three years ago, she had a right hip fracture and underwent hip-replacement surgery. Since this event, her remaining motor function has been gradually deteriorating, as well as sensation.

Enlarged vascular structures were detected on MR imaging on the surface of the lower spinal cord in all 4 patients. High signal intensity was seen in the lower thoracic spinal cord, including the conus medullaris in 2 patients, and 1 patient had bright signal intensity on T2-weighted images up to the level of T9. Two patients had evidence of spinal cord swelling. One patient with minimal leg weakness and numbness below the knee did not have any signal-intensity changes, despite obvious dilated vessels on the dorsal surface of the spinal cord. MR imaging of the lumbar and thoracic spines of the patients with spina bifida showed dilated vascular structures from the cauda equina to both ventral and dorsal surfaces of the upper thoracic spinal cord without signal-intensity change in the spinal cord. None of the patients had subarachnoid hemorrhage.

All fistulas were located between the L3 and L5 levels. Three patients had a single fistula with 1 feeder extending from the anterior spinal artery to a single draining vein in the filum. The dilated single vein reached the conus medullaris and drained into the anterior and posterior surfaces of the cord in 2 cases, but 1 fistula drained only into the anterior spinal vein. One patient with minor symptoms had venous drainage to the radicular veins to the right S1 and left L3 after reaching the spinal cord. Patient 3 (Fig 1) had a high-flow fistula with a dilated artery of the filum terminale draining to a single ectatic vein.

There were distinct venous aneurysms. Patient 4 (Fig 2) with spina bifida had a nidus-type malformation with 3 separate arterial feeders, 1 from the right L4 lumbar artery and 2 from the left lateral sacral artery entering the intradural space at the left S2 level. Superselective injection of the left S2 feeder opacified the anterior spinal artery axis and radiculomedullary artery of the left T9 intercostal artery beyond the nidus, indi- cating that it was a part of the arterial axis of the filum terminale. Venous drainage of this patient was also complex. Two separate draining veins were seen reaching the conus, and 1 small vein drained caudad.

Among 4 patients, 2 (patients 1 and 2) underwent surgical clipping of the fistula, because the caliber of the anterior spinal artery was small and the course was tortuous (Fig 3). The other 2 patients (patients 3 and 4) underwent endovascular treatment. Patient 3, with a high-flow fistula, had a dilated radiculomedullary artery from the right L1 lumbar artery, which was easily catheterized with a 0.016-inch-inner-diameter microcatheter. The venous aneurysm and fistula were occluded with a combination of detachable coils and fibered coils. Patient 4 needed 2 stages of embolization. During the initial procedure, a 0.010 -inch microcatheter was advanced to the feeding pedicle through the right L4 lumbar artery, and embolization of this pedicle was performed by using $n$-BCA. A control angiogram of the left internal iliac artery showed persistent filling of a portion of the nidus from the lateral sacral artery (Fig $2 B$ ). During catheterization of this second feeder, extravasation of a small amount of contrast was observed following a superselective angiogram. We decided to terminate the procedure and treat the rest in a second session. Postprocedural CT showed a small amount of contrast in the intradural space of the L4 level. The remaining nidus was embolized with $n$-BCA after 2 short pushable coils were placed in the artery of the filum terminale distal to the nidus to protect the anterior spinal artery axis. Complete obliteration of the malformation was achieved.

In 2 patients who underwent surgery, fistulas were easily detected after opening the dura. The artery of the filum terminale was recognized extending inferiorly from the anterior spinal artery to the level of the filum terminale, where a small spinal AVF was noted with a draining vein extending cephalad.

Clinical follow-up was performed from 2 months to 6 months. All patients improved neurologically after treatment. Three patients who presented with leg weakness showed improved motor strength, 2 completely recovered and 1 with spina bifida was able to move from the bed to wheelchair without assistance. However, the return of bladder and/or bowel function was slower compared with other neurologic deficits. One patient did not recover urinary function completely, even though motor and sensory deficits resolved completely.

\section{Discussion}

The filum terminale internum is a delicate fibrovascular bundle, approximately $15 \mathrm{~cm}$ in length, extending downward from the apex of the conus medullaris at the level of L1-L2 to the cul de sac of the dura at S2. Its extradural extension, the filum terminale externum, fixes the end of dural tube to the 

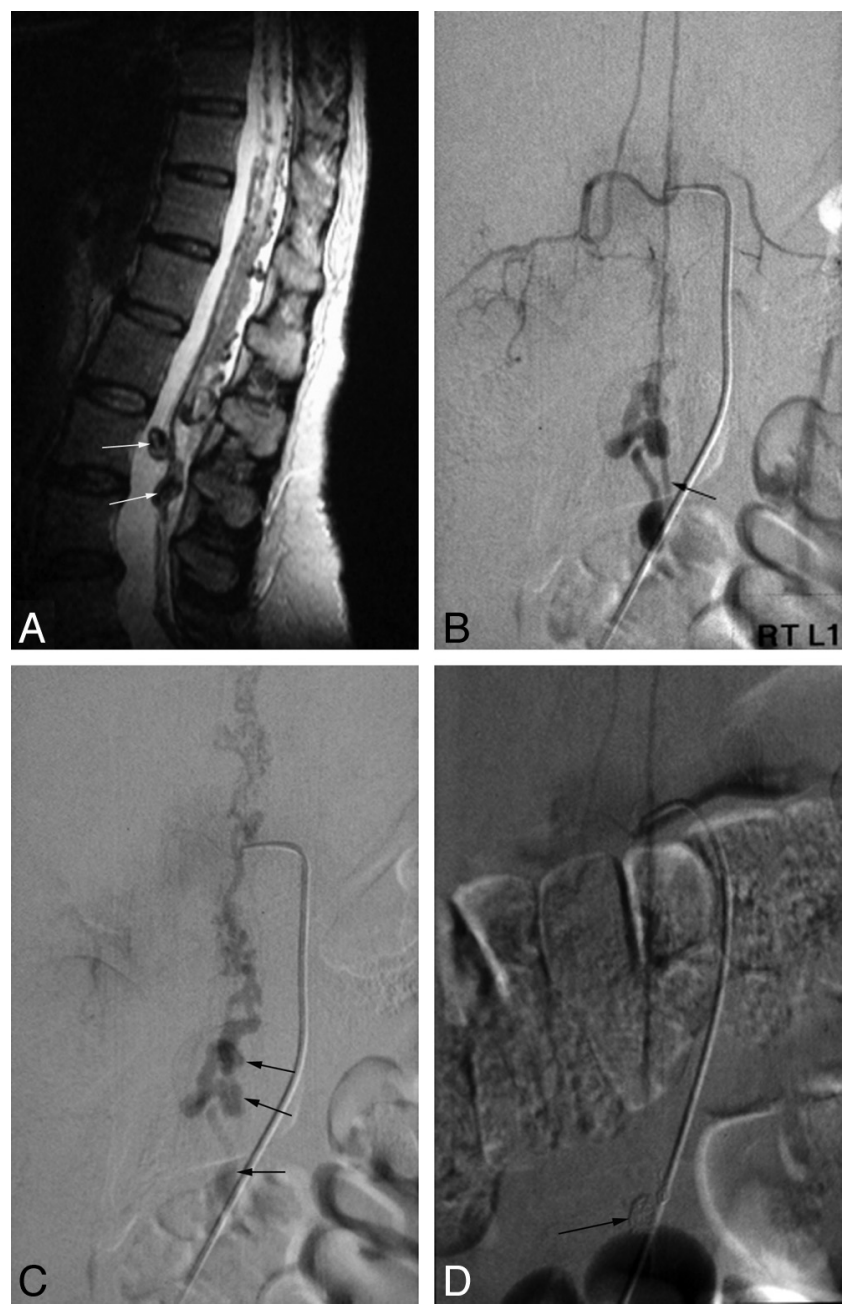

Fig 1. Spinal AVF of the filum terminale (patient 3). A, Sagittal T2-weighted image shows vascular signal-intensity voids with high signal intensity in the lower spinal cord and large signal intensity voids (arrows) on the filum terminale. B and C, Selective angiograms of the right L1 radiculomedullary artery represent an AVF on the filum terminale (L4 level, arrow in B). The feeder of this AVF is the anterior spinal artery and draining vein, which has 3 aneurysmal dilations (arrows in $C$ ) is the perimedullary vein running upward. $D$, $A$ venous aneurysm and the proximal venous side of the AVF are embolized with detachable coils (arrow in $D$ ) and $n$-BCA

posterior end of the coccyx. Histologic study of the human filum terminale by Harmeier in $1933^{3}$ demonstrated the presence of the central canal in the upper one-half of the filum, medullated nerve fibers, and all types of ganglion cells. Abundant connective tissues were observed. Most interesting, he reported the presence of 1 large vein and 2 small arteries in cross-section. He concluded that the filum terminale internum had all the components of the spinal cord; therefore, pathologies in it should be similar to those in the spinal cord. ${ }^{3}$

Vascular anatomy of the filum terminale is unique. A single artery, the artery of the filum terminale, arises from the termination of the anterior spinal axis, as a caudal continuation of the ventral spinal artery. This artery travels in front of the filum and rapidly diminishes in caliber, mostly nourishing the filum itself. It is argued that there are no radicular nerves originating from the filum; therefore, no other artery can supply the filum, including the sacral arteries. ${ }^{6}$ However, Harmeier ${ }^{3}$ illustrated 2 small arteries on a microscopic examination of a cross-section of the filum. In addition, Djindjian et $\mathrm{al}^{5}$ reported the presence of a small artery supplying a coccygeal nerve, which is adherent to the filum in its proximal portion. These observations suggest that it is possible to fill the anterior spinal axis from the lateral sacral artery, which is the arterial supply to the filum terminale externum.

The vein of the filum is a single uniform-caliber vein running from its sacral end to the tip of the conus medullaris. As the artery, it continues to the anterior spinal vein. As seen in the spinal cord, the vein is located behind the artery throughout its course in the filum. Most interesting, the direction of venous flow can be either caudad or cephalad, as observed in some cases of intradural AVMs draining inferiorly to the vein of the filum terminale or dural AVFs in the sacral region draining to the perimedullary venous plexus via the vein of the filum. Our patient with congenital spina bifida had an exceptional complex vascular anatomy. There was supply from the radicular artery of the right $\mathrm{L} 4$ to the nidus-like malformation. In addition, the lateral sacral artery gave a feeder to the malformation, which entered the dura at the sacrum. Its distal segment continued cephalad to the anterior spinal artery. Even a portion of the left T9 segmental artery was opacified by reflux (Fig $1 C$ ). This is probably the branching artery of the filum to the coccygeal nerve as described by Djindjian et al. ${ }^{5}$ Similar arterial supply to a single fistula of the filum terminale was reported by Jin et al. ${ }^{11}$ Venous outflow in this patient was 

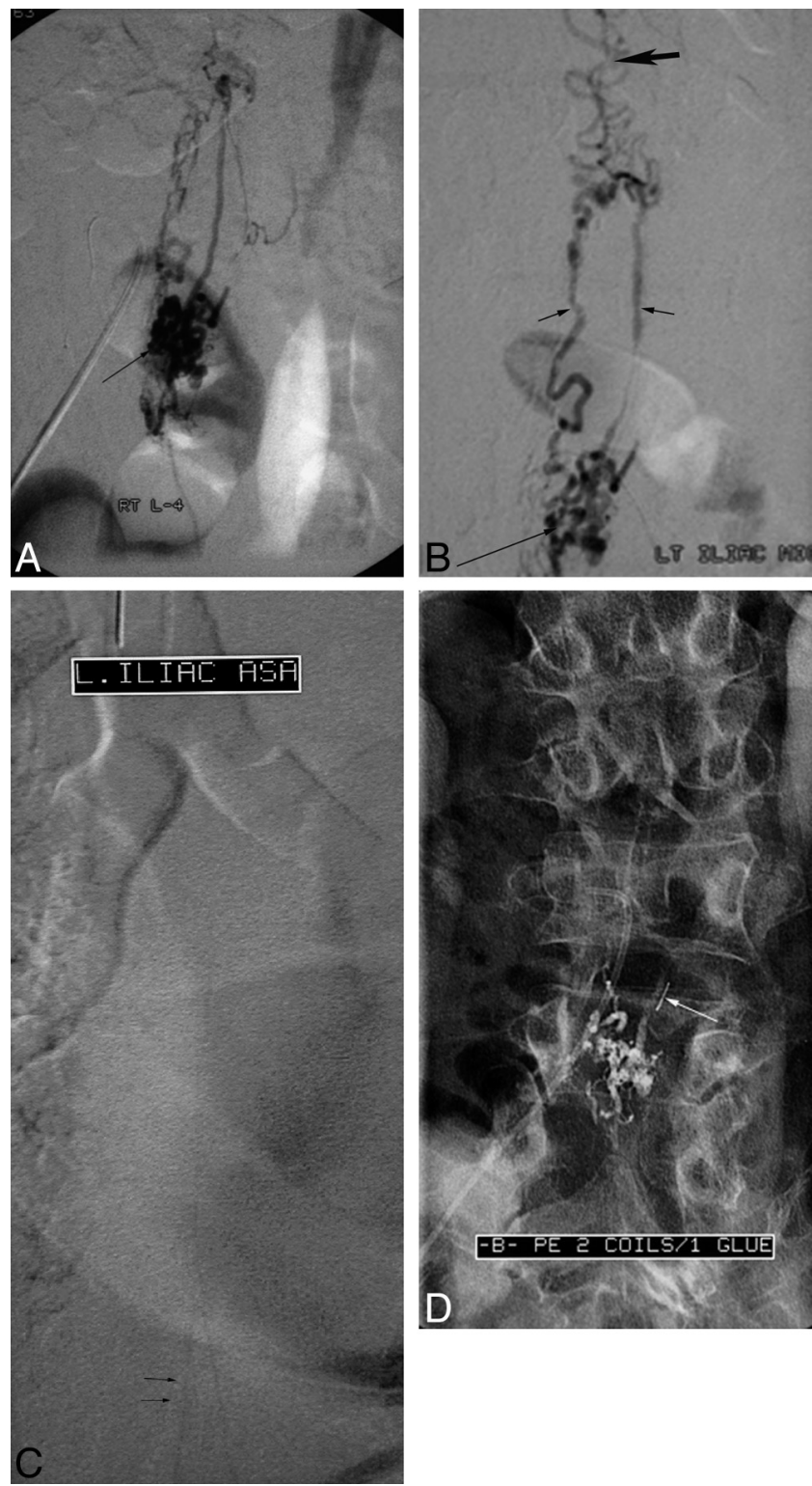

Fig 2. Spinal AVF of the filum terminale (patient 4). $A$, Selective spinal angiogram of the right $L 4$ radiculomedullary artery shows a vascular nidus (arrow) and early draining veins $B$ and $C$, Selective spinal angiograms of the left lateral sacral artery represent the same nidus (long arrow in $B$ ), draining veins. (short arrows in $B$ ), and dilated perimedullary vein running upward (thick arrow in $B$ ) and filling the anterior spinal artery (arrows in $C$ ) beyond the nidus. $D$, Postembolization lumbar spine anteroposterior view shows the embolized nidus, draining veins with $n-\mathrm{BCA}$, an a detachable coil (arrow) for protection of the anterior spinal artery during embolization.

also complex. There were 2 distinct veins filling from the nidus. The perimedullary veins were eventually filled, causing venous hypertension of the spinal cord.

Most of the reported cases of filum terminale AVF showed a rather small-caliber arterial feeder and a longer distance from the segmental artery to the fistula. It would be safer to treat such fistulas by direct surgical exposure and clipping as in 2 of our patients. Two other patients had unusual arterial feeders, which we treated by an endovascular route. One had an extremely high-flow fistula, causing enlargement of the caliber of the anterior spinal axis. The second embolized case also had enlarged feeders from the right L4 and left lateral sacral artery with a nidus.

One interesting observation in clinical presentation was urologic symptoms. In 2 patients with venous hypertension of the spinal cord, urinary symptoms preceded motor weakness, unlike typical spinal dural AVFs. These 2 patients had urinary incontinence at the time of diagnosis and had a much slower recovery from this compared with motor weakness recovery. One patient had persistent residual urine after 10 years, in spite of motor strength returning completely within 6 months. It is possible that the fistula affected perfusion of the filum terminale, interrupting normal function as in the "tight filum terminale syndrome."

In conclusion, AVFs of the filum terminale, in general, are single-hole communications of 1 feeding artery that is a continuation of the anterior spinal artery and a single draining vein. Clinical manifestations and MR images are similar to those of spinal dural AVFs. Such a fistula often causes serious venous hypertension of the spinal cord; therefore, it has to be treated when it is diagnosed. For treatment, surgery is often the primary choice in most cases, but in some instances, endovascular embolization with $n$-BCA and/or coils can be an 


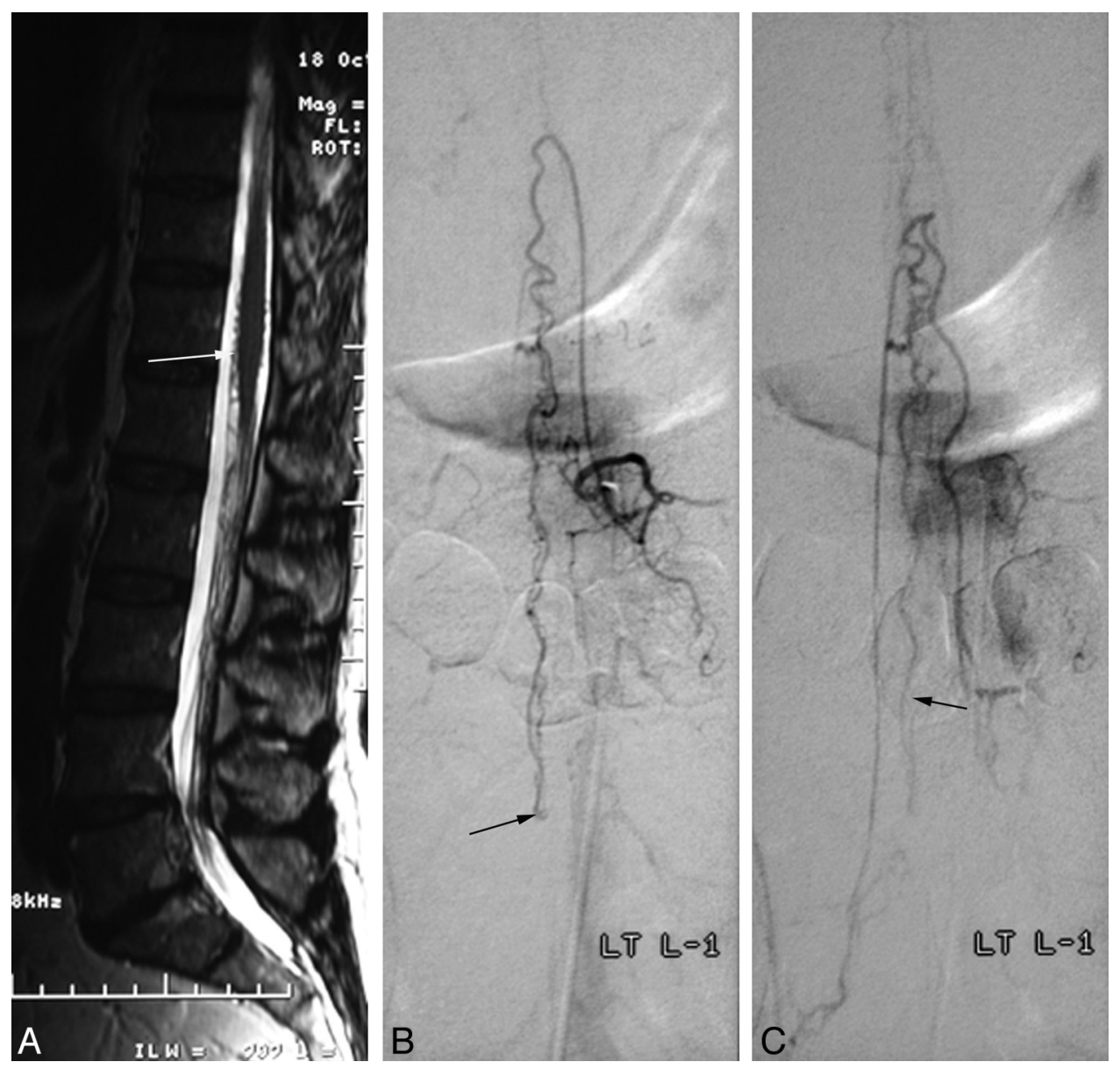

Fig 3. Spinal AVF of the filum terminale (patient 1). A, Sagittal T2-weighted image shows high signal intensity in the conus with vascular signal-intensity voids (arrow) around the conus, raising the suspicion of a vascular spinal abnormality. $B$ and $C$, Selective spinal angiograms show a feeding artery as a continuation of the anterior spinal artery, which is running downward to the site of the AVF on the filum terminale (L3 level, arrow in $B$ ) and the draining vein (arrow in $C$ ), which is running upward.

alternative treatment. Clinical results are good after treatment, especially in progressive neurologic deficits rather than urinary and/or bowel dysfunction.

Disclosures: In Sup Choi, Consultant. Codman Neurovascular, Neurologica. Ownership Interest. Boston Scientific, Johnson and Johnson, Surpass Medical, Neurologica. Details: Stock in these companies. Carlos A. David. Consultant. Codman Neurovascular. Details: Consultant in the role of planning and presenting resident education courses. Ownership Interest. Surpass Medical. Details: private stock ownership.

\section{References}

1. Choi BH, Kim RC, Suzuki M, et al. The ventriculus terminalis and filum terminale of the human spinal cord. Hum Pathol 1992;23:916-20

2. Fontes RB, Saad F, Soares MS, et al. Ultrastructural study of the filum terminale and its elastic fibers. Neurosurgery 2006;58:978-84, discussion 978-84

3. Harmeier J. The normal histology of the intradural filum terminale. Arch Neurol Psychiatry 1933;29:308-16
4. Tarlov I. Structure of the filum terminale. Arch Neurol Psychiatry 1938;40:1-16

5. Djindjian M, Ribeiro A, Ortega E, et al. The normal vascularization of the intradural filum terminale in man. Surg Radiol Anat 1988;10:201-09

6. Lasjaunias P, Berenstein A, Ter Brugge KG, et al. Surgical Neuroangiography. New York: Springer-Verlag; 2001

7. Djindjian M, Djindjian R, Rey A, et al. Intradural extramedullary spinal arterio-venous malformations fed by the anterior spinal artery. Surg Neurol 1977;8:85-93

8. Heros RC, Debrun GM, Ojemann RG, et al. Direct spinal arteriovenous fistula: a new type of spinal AVM-case report. J Neurosurg 1986;64:134-39

9. Mourier KL, Gobin YP, George B, et al. Intradural perimedullary arteriovenous fistulae: results of surgical and endovascular treatment in a series of 35 cases. Neurosurgery 1993;32:885-91, discussion 891

10. Rodesch G, Hurth M, Alvarez H, et al. Classification of spinal cord arteriovenous shunts: proposal for a reappraisal-the Bicêtre experience with 155 consecutive patients treated between 1981 and 1999. Neurosurgery 2002;51: 374-79, discussion 379-80

11. Jin YJ, Kim KJ, Kwon OK, et al. Perimedullary arteriovenous fistula of the filum terminale: case report. Neurosurgery 66:E219-20, discussion E220 